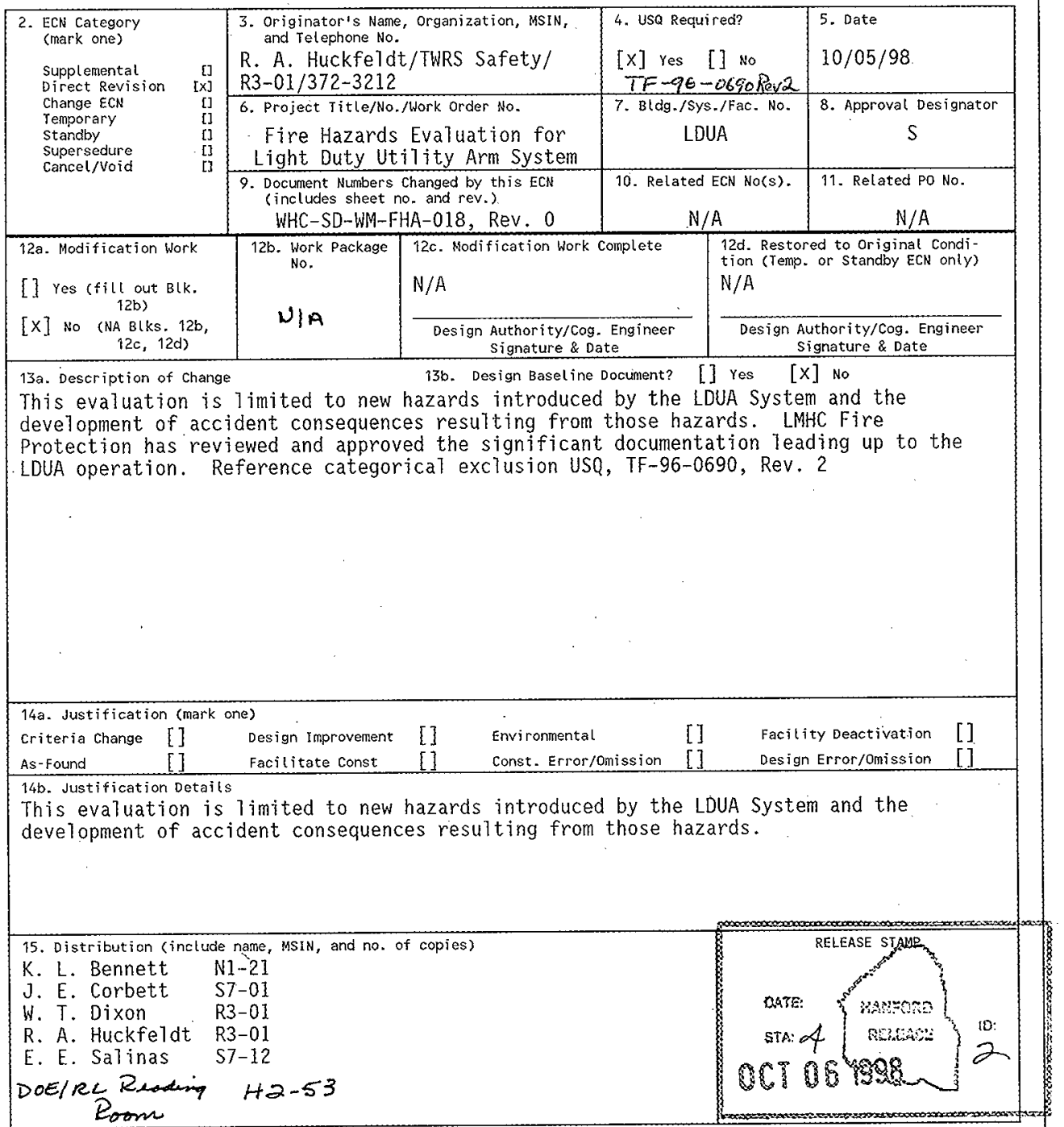

A-7900-013-2 (05/96) GEF095 


\begin{tabular}{|c|c|c|c|c|c|}
\hline \multirow{3}{*}{$\begin{array}{l}\text { 16. Design } \\
\text { Verification } \\
\text { Required } \\
{[] \text { Yes }} \\
{[x] \text { No }}\end{array}$} & \multicolumn{4}{|c|}{ 17. Cost Impact } & 18. Schedule Impact \\
\hline & Additional & $\$$ & Additional & $\$$ & Improvement \\
\hline & Savings & $\$$ & Savings & $\$$ & Detay \\
\hline
\end{tabular}

19. Change Impact Review: Indicate the related documents (other than the engineering documents identified on side 1 ) that will be affected by the change described in Block 13 . Enter the affected document number in Block 20. SDD/DD

Functionat Design Criteria

Operating Specification

Criticality Specification

Conoeptual Design Roport

Equipment Spec.

Const. Spec.

Procurement Spec.

Vendor Information

OM Manual

FSAR/SAR

Safety Equipment List

Radiation Work Permit

Environmental Impact Statement

Environmental Report

Environmenta! Perrnit

[]

[]

[]

[]

[]

[]

[]

[]

[]

[]

[]

[]

[]

[]

[]

[]

SeismicfStress Analysis
Stress/Dosign Repont
Interface Control Drawing
Calibration Procedure
Installation Proccdurc
Maintenance Procedure
Engineering Procedure
Operating Instruction
Operating Procedure
Operational Safety Requirement
IEFD Drowing
Cell Arrangement Drawing
Essential Material Specification
Fac. Proc. Samp. Schedule
Inspection Plan
Inventory Adjustment Request

Tank Calibration Manual

Health Physics Procedure

Spares Multiple Unit Listing

Test Procedures/Specification

Component Index

ASME Coded Item

Human Factor Consideration

Computer Software

Electric Circuit Schedule

ICRS Procedure

Process Control Manualiplan

Process Flow Chart.

Purchase Requisition

Tickler File

20. Other Affected Documents: (NOTE: Documents listed below will not be revised by this ECN.) signatures below indicate that the signing organization has been notified of ather affected documents listed below.

21. Approvals

\section{Design Authority}

Cog. Eng. R. A. Huckfeldt T.Q. Whe Lfeloll

Cog. Hgr. (sue aryety)

QA M. D. Hassebrock

safety W. T. Dixon

Environ.

竹

NSS

other L. S. Krogsrud

J. E. Corbett

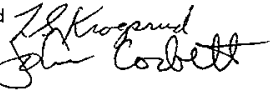

Date

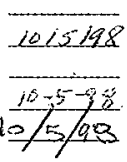

$10 / 5 / 28$ $10 / 5 / 98$ signature

Desigri Agent

PE

QA

Safety

Design

Environ.

other

QEPARIMENT OF ENERGY

Signature or a Control Number that

tracks the Approval signature

ADO1T1ONAL
Date 


\title{
Fire Hazards Evaluation for Light Duty Utility Arm System
}

\author{
R. A. Huckfeldt \\ Lockheed Martin Hanford Corporation, Richland, WA 99352 \\ U.S. Department of Energy Contract DE-AC06-96RL13200
}
EDT/ECN: 192214
UC: 541
Org Code: 7 B100
Charge Code: $\quad$ 25K2
B\&R Code: EW3130010
Total Pages: 2526
$272,6.695$.

Key Words: Light Duty Utility Arm, sensors, tank farms, robotic manipulator, fire hazards

Abstract: In accordance with DOE Order 5480.7A, Fire Protection, a Fire Hazards Analysis must be performed for all new facilities. LMHC Fire Protection has reviewed and approved the significant documentation leading up to the LDUA operation. This includes, but is not limited to, development criteria and drawings, Engineering Task Plan, Qua?ity Assurance Program Plan, and Safety Program Plan. LMHC has provided an appropriate level of fire protection for this activity as documented.

TRADEMARK DISCLAIMER. Reference herein to any specific commercial product, process, or service by trade name, trademark, manufacturer, or otherwise, does not necessarily constitute or imply its endorsement, recommendation, or favoring by the United States Government or any agency thereof or its contractors or subcontractors.

Printed in the United States of America. To obtain copies of this document, contact: Document Control Services, P.0. Box 950, Mailstop H6-08, Richland WA 99352, Phone (509) 372-2420; Fax (509) 376-4989.
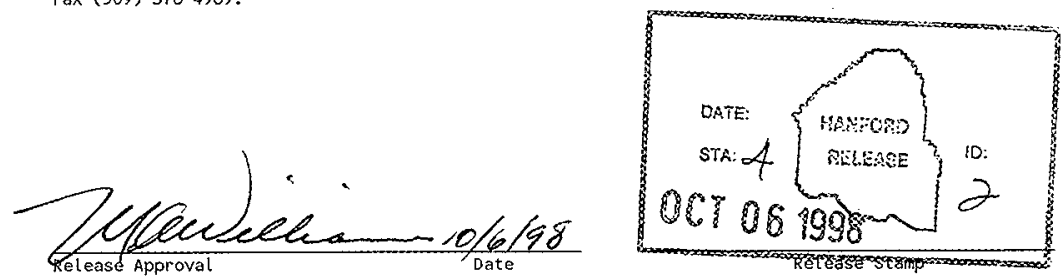

\section{Approved for Public Release}




\section{RECORD OF REVISION}

(1) Document Number

HNF-SD-WM-FHA-018

(2) Title

Fire Hazards Evaluation for the Light Duty Utility Arm System (LDUA)

\begin{tabular}{c|cl} 
(3) Revision & (4) Description of Change - Replace, Add, and Delete Pages \\
\hline Rev. 1 & (7) $\begin{array}{l}\text { This evaluation is Timited to new } \\
\text { hazards introduced by the LDUA system } \\
\text { RS }\end{array}$ & $\begin{array}{l}\text { and the development of accident } \\
\text { consequences resulting from those } \\
\text { hazards. ECN 192214 }\end{array}$ \\
\hline
\end{tabular}

Authorized for Release

(5) Cog. Engr. (6) Cog. Mgr. Date

W. T. pixan 10/5/98

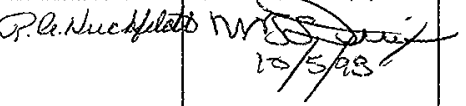
consequences result
hazards. ECN 192214 
HNF-SD-WM-FHA-018, Rev. 1

\section{FIRE HAZARDS EVALUATION}

FOR

\section{LIGHT DUTY UTILITY ARM SYSTEM}

Lockheed Martin Hanford Corporation

September, 1998

Prepared by

R. A. Huckfeldt 
CONTENTS

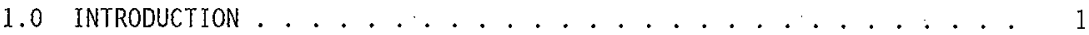

2.0 GENERAL DESCRIPTION ........................ 1

2.1. MOBILE DEPLOYMENT SYSTEM . ....................... . . . 2

2.2 VERTICAL POSITIONING MAST . . . . . . . . . . . . . . 2

2.3 LIGHT DUTY UTILITY ARM . . . . . . . . . . . . . . . . 3

2.4 TRIC SYSTEM . . . . . . . . . . . . . . . . 4

2.5 OPERATIONS CONTROL CENTER ................ 4

3.0 PROTECTION OF ESSENTIAL SAFETY CLASS EQUIPMENT . . . . . . . . . . . . 4

4.0 FIRE PROTECTION FEATURES . . . . . . . . . . . . . . . . . 4

5.0 DESCRIPTION OF FIRE HAZARDS . . . . . . . . . . . . . . . 5

5.1 TANK RISER INTERFACE AND CONFINEMENT . . . . . . . . . . . . . . 5

5.2 HYDRAULIC SYSTEM ........................ . . . . . . . 6

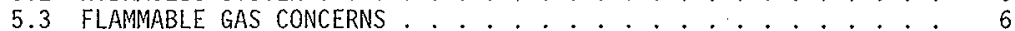

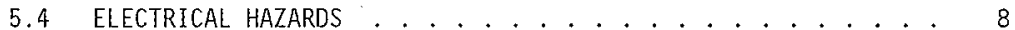

6.0 LIFE SAFETY CONSIDERATIONS . . . . . . . . . . . . . . . . 9

7.0 CRITICAL PROCESS EQUIPMENT . . . . . . . . . . . . . . . . 9

8.0 HIGH VALUE PROPERTY . . . . . . . . . . . . . . . . . . . . . 9

9.0 DAMAGE POTENTIAL . . . . . . . . . . . . . . . . . . . . . . 9

10.0 FIRE DEPARTMENT/BRIGADE RESPONSE . . . . . . . . . . . . . . . 10

11.0 RECOVERY POTENTIAL. . . . . . . . . . . . . . . . . . 10

12.0 POTENTIAL FOR TOXIC, BIOLOGICAL, AND/OR RADIATION INCIDENT DUE TO

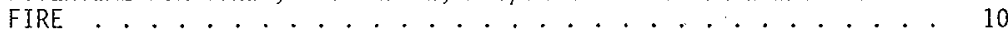

13.0 EMERGENCY PLANNING . . . . . . . . . . . . . . . . . . . . 10

14.0 SECURITY AND SAFEGUARDS CONSIDERATIONS RELATED TO FIRE PROTECTION . 10

15.0 NATURAL HAZARDS IMPACT ON FIRE SAFETY . . . . . . . . . . . . 11

15.1 FLOODS . . . . . . . . . . . . . . . . . . 11

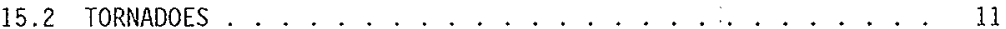

15.3 EARTHQUAKES . . . . . . . . . . . . . . . . 11

16.0 EXPOSURE FIRE POTENTIAL . . . . . . . . . . . . . . . . . 11

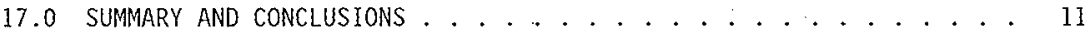

18.0 FINDINGS . . . . . . . . . . . . . . . . . . . . . 11

19.0 REFERENCES ........................... 11 
HNF-SD-WM-FHA-018, Rev. 1 Page 1

\section{I.0 INTRODUCTION}

In accordance with DOE Order 5480.7A, Fire Protection, a Fire Hazards Analysis (FHA) must be performed for all new facilities. The purpose of the analysis is to comprehensively assess the risk from fire within individual fire areas in relation to proposed fire protection so as to ascertain whether the fire protection objectives of the order are met. The order acknowiedges a graded approach commensurate with the hazards involved. Because the Light Duty Utility Arm (LDUA) is an activity within the Tank Farms which is not addressed in an existing FHA, LMHC has provided this fire protection evaluation per the criteria of DOE Order 5480.7A. It should be noted that this evaluation is limited to new hazards introduced by the LDUA System and the development of accident consequences resulting from those hazards. It is not the intent to perform any redundant analyses to that currently existing within tank farm authorization basis documents. It should be noted that this analysis currently 7 imits the LDUA operation to Facility Group 3 Tanks. Section 3.0 provides details for this limitation.

LMHC Fire Protection has reviewed and approved the significant documentation leading up the LDUA operation. This includes, but is not 1 imited to: development criteria and drawings, Engineering Task Plan, Quality Assurance Program PIan, and Safety Program Plan. LMHC has provided an appropriate level of fire protection for this activity as documented by the following.

\subsection{GENERAL DESCRIPTION}

The LDUA System deploys a family of tools and sensors, called end effectors, into underground storage tanks by means of a robotic arm on the end of a telescoping mast, and collects and manages the data that they generate. Access into the tank is gained through existing risers. A Mobile Deployment system transports the mast and arm between tanks and positions them over a 12-inch tank riser for deployment. Ancillary subsystems support the main deployment equipment, performing such functions as maintaining confinement of the tank atmosphere; decontamination of mast, arm, and end effector; power distribution; and observation of in-tank operations. The LDUA system is operated from the remote Operations Control Trailer located outside the perimeter fence of the tank farm, up to 900 feet from the deployment vehicle.

The LDUA System provides the capability to reach locations within the tank and waste surface that are not directly under the access risers. This capability has not been available to tank farm operations before and is one of the primary reasons that the LDUA System was developed. The LDUA System is designed to operate safely in the hazardous (high radiation, flammable gasses, corrosive chemicals) environment of underground storage tanks at the Hanford Site as we 17 as underground storage tanks located at other DOE sites. It is a) so designed to accept new end effectors and adapt to new missions with little disruption to the existing system. 
HNF-SD-WM-FHA-018, Rev. 1 Page 2

\subsection{MOBILE DEPLOYMENT SYSTEM}

The Mobile Deployment System (MDS) is used to transport the LDUA between and within tank farms for deployment. It is based on a single axle flatbed truck of noncombustible construction with a 16-foot wheelbase and an overall length of less than 25 feet. The truck has outriggers which extend and lock to provide a firm base for deployment into the tank. The MDS is equipped with the $X-Y-R o l]$ Table that allows the Vertical Positioning Mast (VPM) housing to be elevated to the vertical position for deployment and lowered to the horizontal position for transport (the VPM housing is 35 feet long). The $X-Y$ Roll Table also provides fine positioning control of the $X$ and $Y$ axes of translation (over a range of 6 inches), and the pitch and roll axes (over a range of plus or minus 5 degrees). These fine control motions are used to align the VPM with the riser to ensure free passage of the VPM into the tank. The positioning table axes have mechanical locks that can be set to prevent slippage once final position has been achieved. The VPM housing has electronic inclinometers that can detect any ground settling or other unwanted motion that may affect the alignment of the VPM to the riser.

\subsection{VERTICAL POSITIONING MAST}

The Vertical Positioning Mast (VPM) provides the gross vertical positioning of the L.DUA within the waste tank. When fully deployed, the VPM can reach 47 feet below the bottom of the VPM housing (measured at the shoulder pitch joint of the LDUA). This means that the end effector can reach the bottom of the deepest Hanford single shell tank (nominally 50 feet below grade). The VPM is supported by a truss frame constructed of 6061-T6 aluminum box tubing. This frame is covered by aluminum panels to form a housing that provides a sealed contamination boundary in both the deployed and transport modes. The VPM housing has a standard 14-inch gate valve at the bottom which is remotely. operated to seal the housing or to allow the VPM and LDUA to emerge.

The VPM has two telescoping tubular sections. The LDUA is attached to the bottom of the inner VPM tube and both are wholly contained inside the outer VPM tube when fully retracted. Each tube is driven by a hydraulic winch through a pair of steel cables (for redundancy). The winches are equipped with fail-safe brakes. The position of each tube is accurately sensed by resolvers that are actuated by small cables attached to the tubes. The VPM can move with an accuracy of 0.5 inch and the ability to return to a given position within 0.2 inch. The resolvers provide a resolution of better than 0.05 inch. The LDUA control system permits selection of the sequence of motion of the VPM tube sections - e.g., outer tube moves first or inner tube moves first. Outer tube first mode protects the LDUA during transit through the riser, but inner tube first mode al lows best coverage of decontamination spray. The VPM tubes are made of 304L stainless steel. The outer VPM tube is carried on linear ball bearings that travel on rails mounted on a large member of the aluminum truss frame. The rails are accurately aligned to provide smooth motion of the VPM with negligible runout. The inner VPM tube is carried on a set of rollers that travel on the inside diameter of the outer VPM tube. The VPM has analog speed control from zero to 15 feet per minute. 
HNF-SD-WM-FHA-018, Rev. 1

Page 3

\subsection{LIGHT DUTY UTILITY ARM}

The LDUA is a robotic manipulator that has seven degrees of freedom that provide dexterity to reach around obstructions in the tank while orientating and positioning end effectors to any surface within its operating envelope. The operating envelope of the LDUA extends out to 9 feet from the centerline of the VPM. The LDUA has a maximum reach of 13.5 feet (shoulder to wrist) when fully extended. It can deploy into a tank with as little as 6 feet of clearance between the bottom of the riser and the surface of the waste. Five of the joints of the LDUA are hydraulically actuated and two (wrist roll and shoulder yaw) are electrically actuated. All joints are equipped with brakes. A backup battery power supply provides up to four hours of brake actuation in the event that main power to the LDUA System is lost. If all power to the LDUA is removed, its joints will slowly relax allowing it to be recovered through the riser.

The maximum payload of the LDUA is 75 pounds, with a moment loading of 1000 inch-pounds at the Tool Interface Plate (TIP) mating surface and 150 inchpounds moment about the wrist roll axis. At the nominal payload of 50 pounds, the LDUA is designed to have a repeatability of plus or minus 0.2 inches from an established starting point and a positional error of plus or minus 0.5 inches. The LDUA Controller is designed to compensate for static deflection of the VPM under load in order to minimize the end-to-end error of the whole system. The LDUA is equipped with resolvers on all of its joints that provide a resolution of better than 0.050 inch. The LDUA is constructed almost entirely of 17-4PH stainless steel which provides high strength and corrosion resistance. It is a completely sealed unit that carries all of its utilities internally and it has flexible boots at each joint to maintain the seal. There is a video camera and lights in the shoulder section of the LDUA that can pan and tilt to observe most of the working envelope.

The LDUA has a Tool Interface Plate (TIP) at its wrist for mounting end effectors. The TIP provides a standard mounting surface common to each of the LDUA deployed end effectors that are used in the underground storage tanks. It consists of two plates, with the master plate located on the wrist of the LDUA, and the slave plate located on the end effector. The interface between the plates is sealed against the tank atmosphere and contents. The TIP has a set of guide pins that ensure proper alignment of the two TIP plates and there are three mechanical latches that positively engage and lock the TIP halves together. A set of electrical and pneumatic utility services are provided for end effector operation. These are carried through the TIP by connectors within the sealed interior of the TIP. These utility services includes 30 shielded twisted pairs (for signals), 4 shielded triples (for power), 3 coaxial cables (for video or other high-speed signals), one hose (for purging the end effectors), and 2 hoses (for powering pneumatic actuators). They are carried to the At-Tank Instrument Enclosure (ATIE) where they are available to the end effector's support equipment. A 6 axis force/torque sensor is provided in the LDUA's wrist joint. It is not integrated into the control system, but its output is available to be read. 
HNF-SD-WM-FHA-018, Rev, 1 Page 4

\subsection{TRIC SYSTEM}

The Tank Riser Interface and Confinement (TRIC) provides an interface between the LDUA system and the waste tank riser. It is used for change-out of end effectors, minor maintenance tasks, and containment of the tank atmosphere. A decontamination system is provided for routine cleaning of the VPM, LDUA, and end effectors to levels acceptable for transportation within the Hanford site.

\subsection{OPERATIONS CONTROL CENTER}

The Operations Control Center encompasses most of the control and data acquisition equipment for the LDUA system. It houses and interconnects the equipment and provides the interfaces for personnel to operate the LDUA integrated system. It consists of the Operations and control Trailer (OCT), the At-Tank Instrument Enclosure (ATIE), the Supervisory Control and Data Acquisition System (SCADAS), and the Control Network.

\subsection{PROTECTION OF ESSENTIAL SAFETY CLASS EQUIPMENT}

A Safety Equipment List (SEL) has been developed for the LDUA System. The SEL only applies to LDUA activities in Facility Group 3 tanks. For Facility Group 3 tanks, only small localized Gas Release Events are anticipated. These GRES wi 71 not cause tank head space to reach flammable gas concentrations in excess of $25 \%$ of the LEL (HNF-SD-WM-B10-001) and therefore any ignition of flammable gases will be localized. The localized ignition of flammable gases will not cause a waste tank fire, explosion or dome collapse. For this reason, the LDUA SSCS that prevent ignition of $f l$ ammable gases are classified as General Service, Defence in Depth. It is anticipated that a higher safety class designator may be necessary prior to using this equipment in Facility Groups 1 \& 2 tanks.

\subsection{FIRE PROTECTION FEATURES}

The LDUA System is purged by a constant low flow of instrument grade (clean, low moisture) air. This Type $X$ purge flow enables it to meet National Electric Code requirements for operation in Class 1 , Division 1 , Group $B$ flammable atmospheres by maintaining the internal pressure of the end effector, LDUA, and VPM above the pressure of the external atmosphere (in accordance with National Fire Protection Association (NFPA) 496. This pressure differential also keeps the interior surfaces of these components from becoming contaminated in the event of seal leakage. Purge air is carried into the end effector by one of the pneumatic utility service lines. The purge air is released into the end effector and flows through it into the LDUA via vent openings provided in the TIP. The purge flow continues through the whole length of the LOUA and into the inner and then outer VPM tubes. From the outer VPM tube, it passes into the VPM housing from where it is exhausted into the TRIC. Differential pressure sensors monitor the purge pressure in the inner VPM tube and the VPM housing. These sensors are referenced to the tank pressure, which is obtained by a pressure tap below the Riser Isolation Valve. An alarm is generated if the pressure falls below the required level 
HNF-SD-WM-FHA-018, Rev. 1 Page 5

(Type $Z$ purge). In addition, the LDUA control system can be selectively enabled to remove all electrical power from the purged volume (Type $X$ purge, this mode is enabled when operating in tanks with flammable atmospheres and disabled when operating in non-flammable tanks). The system is designed so that no single point failures could prevent the removal of electrical power when purge pressure is insufficient.

\subsection{DESCRIPTION OF FIRE HAZARDS}

\subsection{TANK RISER INTERFACE AND CONFINEMENT}

The confinement enclosure provides radiological confinement when the access riser is open, such as when the LDUA is deployed into the tank. The sides of the enclosure are transparent polycarbonate plastic and six sets of gloveports (with Hypalon gloves) are provided to allow minor hands-on activities to be performed on the LDUA or the end effector. A large door on the side of the enclosure provides access for the exchange of end effectors on the LDUA.

The Mast Housing Adapter provides a flexible sealed coupling between the top of the confinement enclosure and the bottom of the VPM Housing. Flexibility is necessary to compensate for the differences in riser elevations and different ground surface contours. Flexibility is also necessary to allow for the movement of the VPM Housing during the process of aligning it to the riser. Ventilation of the enclosure is provided by aspiration through a HEPA filter to atmosphere.

It is recognized that this unit must remain portable and al so be subjected to an outside environment consisting of cold, heat, wind, rain etc. Therefore, the construction must be relatively light and yet durable. Also, it was necessary to give operators adequate viewing of the inside, A stainless steel frame with polycarbonate windows was chosen. Polycarbonate is light, durable, and inherently a fire retardant plastic. The DOE Standard for Glovebox Fire Protection was reviewed to determine its applicability to this enclosure. It was determined that the TRIC really does not fit well into the criteria of this standard. However, this standard does acknowledge polycarbonate as having better fire retardant qualities than most other plastics and accepts it when the use of noncombustible materials is not possible.

Below the TRIC enclosure is the Decon Module. There are synthetic rubber wipers between these units to remove excess water from the mast and arm following decontamination using a waterspray system. The wipers are made of "Buna N". This material is a copolymer made from butadiene and acrylonitrile monomers. It can withstand temperatures up to 300 degrees $F$ without being damaged. As stated later in this report, the maximum possible temperature that could be reached, assuming heater control failure, is 450 degrees $F$. This temperature may cause permanent damage to the wipers, but is incapable of causing ignition.

No fire protection issues are identified regarding the TRIC design. 
HNF-SD-WM-FHA-018, Rev. 1

Page 6

\subsection{HYDRAULIC SYSTEM}

The hydraulic system consists of the Hydraulic Power Unit (HPU), Hydraulic Piping Distribution Network (HPDN), and the Subsystems Hydraulics. The HPU is located on the MDS truck. The main hydraulic pump delivers a maximum flow of $10 \mathrm{GPM}$ at a nominal pressure of 2500 PSI (maximum 3000 PSI). There is a dedicated filtration system and cooling pump. There is also a heater to raise the hydrautic oil temperature to a nominal 20 degrees $C$. (Temperature sensor automatically shuts down system on high oil temperature) The 60-gallon reservoir serving this system has a " $C$ " shaped configuration. This architecture assures that an oil leak of 5 gallons will provide a change in oil level of 8 inches which can easily be detected by the level sensor and shut down the hydraulic system. The system shuts down automatically due to loss of oil volume. The hydraulic oil used is mineral oil shell TelTus 32 which has a flash point of 370 degrees $F$ and has low toxicity. The HPDN comprises piping and flexible hoses which distribute the pressurized hydraulic 0 il to the subsystems. Subsystem Hydraulics comprise Hydraul ic control modules, hydraulic actuators and hydraulic hoses.

A high pressure spray leak within the LDUA consisting of approximately 5 gallons of $0 i 7$ would be considered a credible accident scenario. Since the oil has a 370 degree flash point, it is normally not ignitable. However, a high pressure spray leak will atomize the $0 i 1$ and make ignition possible. All electrical devices within the LDUA were evaluated as potential ignition sources. There were no devices found to be incendive under normal operating conditions. All devices were low heat producers, non sparking, and tow energy. In effect, the electrical system within the LDUA are nonincendive under normal operating conditions similar to equipment approved for Class I, Division 2 environments. No credible fire is postulated.

\subsection{FLAMMABLE GAS CONCERNS}

Flammable gases are generated within the waste by several processes within the tank including: 1) radiolysis of the waste which produces hydrogen and ammonia; 2) corrosion of the steel 1 iner which produces hydrogen; and 3 ) chemical decomposition of the waste which produces hydrogen, methane, ammonia, and nitrous oxide. Under normal conditions a steady state condition exists in which the gas production rate equals the tank headspace gas addition rate. The steady state gas concentrations are then dependent upon the generation rate and the headspace ventilation rate.

It has been abserved in some tanks that gases generated within the waste accumulate within the waste rather than being released at the surface in a steady fashion. This leads to accumulations of gas which has been released in an episodic fashion. While tank 241-SY-101 has had the greatest leve?

fluctuations and documented GRE's, evidence of the presence of accumulated gas has been found by Nichols et al. (1994) in SST FGWL tanks and by Hodgson et a7. (1995) in additional non-FGUL SST'S. The magnitude of GRE'S for SY-101 have been deduced from available data in LA-UR-92-3196 Rev 14. The magnitude of the largest documented GRE in SY -101 is approximately $300 \mathrm{~m}^{3}$. 
HNF-SD-WM-FHA-018, Rev. 1

Page 7

Little is known about the details of GRE's though the phenomenon is believed to result from bulk density changes in the nonconvective (NC) layer which result from gas accumulation, leading to a Rayleigh-Taylor instability. While the current level of understanding of GRE's is not sufficient to allow great confidence, it is thought that the GRE magnitude is bounded by the SY-10] results. However, major uncertainties in gas composition and amount lead to major uncertainties in the hazards of GRE's.

The mechanisms of bubble retention has been studied by Gauglitz et al. (1994). They reviewed the relevant literature and studied the morphology and rheology of bubbles within sludges. They found that bubbles within a sludge form into three regions; dendritic bubbles at the base of the sludge, large fractures containing gas in the middle region, and round bubbles in the upper region. This work gives insights into the structure of gas held within the sludge.

The release of gas from with in the sludge has largely been attributed to a Raleigh-Taylor instability in which the gas generation causes the sludge layer to have a lower bulk density than the supernatant above. This unstable configuration gives rise to a roll-over which results in a GRE. This phenomena has primarily been studied in conjunction with SY-101 which has sludge and supernatant layers of roughly equal depths. Modeling of the phenomena indicates that the fraction of gases released is markediy reduced as the depth of the supernatant is reduced (Allemann 1995). This is primarily due to a suppression of the roll-over due to the thin upper layer. Because the SST's have much less supernatant than SY-101, it is expected that a GRE resulting from this mechanism would be much less severe than in $\$ Y-101$. Other gas release mechanisms have been discussed including: rising local gas bubbles, mud pot (local yielded sludge chimney), disruption causing release, fraction of "dry" sludge, and drying out of salt cake.

The local gas bubble mechanism is not highly regarded as a mechanism. They would be restricted to $1 \mathrm{~m}$ bubbles or less and cannot easily explain observed behavior. The mud pot mechanism involves the release of dendritic gases via an opening to the surface which is suddenly created. This can lead to a 1 arge release with a visual appearance of a bubbling mud pot. Visual evidence of this behavior in photos of waste surfaces in SST has been observed. The size of the release could be as muct as $80 \%$ of the dendritic gas over periods of minutes to hours. The disruption induced release is much the same as the mud pot mechanism except that the release is initiated by an external disruption of the waste which could induced larger flow rates if the disruption is large in size. The fraction of dry sludge is not thought to be a viable mechanism of sudden release due both to the weakness of the surface sludge layer and the porosity of the layer. The dry-out of salt cake can potentially lead to the release of gases retained between sludge and salt cake layers in which the wet salt cake acts as a gasket which seal the gas.

With the mixer pump mitigation of Tank 101-SY, tanks currently exhibiting GRES have not approached a head space flammable concentration. The most significant gas releases that have recently been witnessed in tanks involve activities where waste intrusion is necessary. Flammable concentrations of waste gases have been trapped in equipment at the release point prior to being 
HNF-SD-WM-FHA-018, Rev. 1

Page 8

diluted by the large volume of air in the vapor space. Current designs for electrical equipment where this situation may occur must meet National Electrical Code requirements for Class I, Division 1, Group B locations. Other situations may require compliance with Class I, Division 2, Group B requirements. The LDUA has been designed to operate in either a Type $X$ purge mode or Type $Z$ purge mode which complies with each classifications respectively.

Administrative and engineering controls are also provided to ensure the LDUA System is properly grounded and bonded to prevent electrostatic sparks. The arm itself, except for the Tool Interface Plate (TIP), is stainless steel, which minimizes the potential of mechanical sparks that could be caused as the arm passes through the riser. The TIP is made of titanium. Titanium has a thermodynamic potential for reduction of iron oxide (rust) which could produce a thermite flash reaction. This could be initiated by colliding the TIP into a rusty steel riser. A "Hastaloy" coating was applied to much of the TIP to control this hazard.

\subsection{ELECTRICAL HAZARDS}

The LDUA, mast, and end effectors are designed as a pressurized/purged enclosure having the capability of meeting a Type $X$ or Type $Z$ purging in accordance with NFPA 496 . Type $X$ purging allows general wiring methods to be used in $\mathrm{Class} I$, Division 1 environments. Type $Z$ purging allows general purpose wiring methods to be used in Class 1 , Division 2 environments. A11 wiring and electrical equipment used is Listed and have short circuit/overload protection. The design provides adequate protection for preventing electrically initiated fire in the arm and mast. It also prevents the arm, mast, and end effectors from becoming an ignition source for gases that might be released from the waste.

The decontamination module located below the TRIC is equipped with 1500 watts of heating for freeze protection provided by thermostatically controlled resistance type heating blankets. The blankets are constructed of copper wiring surrounded by silicon rubber impregnated with fiberglass insulation. They are UL Listed. All electrics are physically isolated from the tank vapor space and can not come into contact with any flammable gases. The blankets are supplied by a single 15 ampere, 208 volt circuit breaker. The normal failure mode for the thermostat is open. Even if the thermostats failed closed and the circuit breakers failed to operate, element failure will occur at less than $450 \mathrm{~F}$. Also included in this module are four contamination detectors. These units have adequate circuit protection and are physicaliy isolated from the tank vapor space. Neither of these systems represent potential ignition sources.

The remainder of the LDUA System will be located at ground level inside and outside of the tank farm fenced areas and do not represent any new or different hazards than those currently identified in tank farm authorization basis documents. 
HNF-SD-WM-FHA-018, Rev. 1

Page 9

\subsection{LIFE SAFETY CONSIDERATIONS}

The control trailer is designed in accordance with the applicable requirements of NFPA 101. The LDUA System does not present any identifiable life safety considerations with respect to NFPA 101 (1994), Life Safety Code.

\subsection{CRITICAL PROCESS EQUIPMENT}

There are no critical process equipment associated with LDUA System.

\subsection{HIGH VALUE PROPERTY}

The estimated replacement values are as follows:

Operations Control Trailer
LDUA/MDS/VPM
TRIC
ATIE
Decon Trailer
Overview Camera System
Power Distribution Skid
End Effectors

$\begin{array}{lr}\$ & 465,000 \\ \$ 2,000,000 \\ \$ & 80,000 \\ \$ & 60,000 \\ \$ & 40,000 \\ \$ & 70,000 \\ \$ & 40,000 \\ \$ 70,000 \text { to } \$ 120,000\end{array}$

\subsection{DAMAGE POTENTIAL}

The Tank Farm Fire Hazard Analys is (FHA) covers various types of tank internal and external ignition sources as well as the consequences resulting from associated tank accidents. The LDUA System does not introduce any new or different hazards than those analyzed. This evaluation will therefore be limited to fire losses involving LDUA equipment only.

A Maximum Possible Fire Loss is the value of the property within a fire area, unless a fire hazard analysis demonstrates a lesser or greater loss potential. Due to the lack of an automatic fire suppression system, the Maximum Credible Fire Loss (MCFL) is equal to the Maximum Possible Fire Loss (MPFL). This activity is performed outside and each of the major components of the system are sufficiently separated as to be in separate fire areas. The LDUA/MDS/VPM has the highest replacement cost, the most potential ignition sources, and significant combustible loading. Therefore it was selected to represent the MPFL. If a sufficient fire initiating event occurred to totally destroy this trailer, the estimated loss would be $\$ 2,000,000$ plus clean-up. Radiological consequences are expected to be minimal because it is expected that the LDUA and end effectors will be essentially decontaminated by the water decontamination system each time the arm is retracted. If this were to be a facility, the total loss would exceed the $\$ 1,000,000$ loss 1 imit required by DOE. Order $5480.7 \mathrm{~A}$ and automatic sprinkler. protection would be necessary. Providing sprinkler protection for this vehicle is not possible. However, due to the vehicle design, the only. conceivable way for a loss of this magnitude would be from an exposure fire. Each placement of the LDUA will be reviewed and approved by Fire Protection Engineering to assure compliance with NFPA $80 \mathrm{~A}$. 
HNF-SD-WM-FHA-018, Rev. 1

Page 10

It should also be noted that the Operations Control Trailer has a replacement cost in excess of $\$ 250,000$. In order to comply with DOE EV-0043, Fire Protection For Portable Structures, an automatic sprinkler system is needed. Due to the need for mobility of this unit, such protection is not possible. The Standard includes an exception allowing the local authority having jurisdiction (DOE-RL) to give relief from this requirement in such a situation. Westinghouse Hanford Company requested concurrence from DOE-RL for an exception to this requirement. The request was granted (Attachment 1).

\subsection{FIRE DEPARTMENT/BRIGADE RESPONSE}

The on-site, fully-manned, constantiy attended Hanford Fire Department is well trained and adequately equipped to respond to all anticipated fire scenarios.

\subsection{RECOVERY POTENTIAL}

The anticipated recovery from the MCFL/MPFL, would include clean-up and the procurement and construction of another vehicle. The estimated replacement time for a new vehicle is 8 to 10 months.

This category is further covered under Item 13, Emergency Planning.

12.0 POTENTIAL FOR TOXIC, BIOLOGICAL, AND/OR RADIATION INCIDENT DUE TO FIRE

Exposures to radiological hazards is evaluated in the Safety Assessment. The hydraulic fluid is a mineral oil and according to the MSDS contains no hazardous chemicals.

\subsection{EMERGENCY PLANNING}

HNF-IP-0842, Waste Tanks Administration, for Tank Waste Remediation Operations, provides a system of planred responses to minimize risks to personnel, equipment, buildings, and the environment in the event of emergencies including fire.

Emergency planning for Tank Farms is covered in HNF-IP-0263, Building Emergency Plan (Hazardous Facility). This document covers general emergencies that could occur throughout the facility, such as fire, explosion, natural hazards, toxic release, etc. There are no specific emergency plans for the LDUA System.

\subsection{SECURITY AND SAFEGUARDS CONSIDERATIONS RELATED TO FIRE PROTECTION}

The Tank Farms are controlled access areas. Around-the-clock surveillance is maintained for the protection of government property. The Hanford Patrol and Benton County Sheriff's Deputies maintain a continuous presence of armed guards to provide the Hanford Site security. 
HNF-SD-WM-FHA-018, Rev. 1

Page 11

\subsection{NATURAL HAZARDS IMPACT ON FIRE SAFETY}

\subsection{FLOODS}

The 200 Areas are situated on a plateau, and because of the elevation, the structures are not susceptible to catastrophic flooding even by the "probable maximum flood" postulated by the U.S. Army Corps of Engineers (ERDA 1975) for the Columbia River Basin. The maximum 24 hour precipitation expected to occur once in 1,000 years is $6.8 \mathrm{~cm}$ (Stone et al. 1983).

\subsection{TORNADOES}

The Pacific Northwest is one of the areas of the country with the lowest frequency of tornadoes. The entire state of Washington has an average tornado frequency of less than one per year. An analysis of the Hanford site concludes that the probability of a tornado hitting any particular onsite facility is six chances in a mition during any one year.

\subsection{EARTHQUAKES}

Eastern Washington is a region of low-to-moderate seismicity. Based on the seismic history since 1840, the U.S. Coast and Geodetic Survey has designated Eastern Washington as Zone 2 seismic probability, implying a potential for moderate damage from earthquakes.

\subsection{EXPOSURE FIRE POTENTIAL}

It wi7l be necessary to ensure that there are no significant structures located near the area where this equipment will be deployed. Prior to deployment review and approval of equipment placement by LMHC Fire Protection is required to assure these activities meet the applicable exposure separation criteria established in NFPA 80A, Recommended Practice for Protection of Buildings from Exterior Fire Exposures.

\subsection{SUMMARY AND CONCLUSIONS}

The applicable objectives of DOE Order 5480.7A have been reviewed and are in compliance.

\subsection{FINDINGS}

None

\subsection{REFERENCES}

[1] Altemann, R. T., et al,, 1995, A Discussion of Some Mechanisms for Sudden Gas Release From Single Shell Waste Tanks at Hanford, Pacific Northwest Laboratory, PNL-WTS-101095. 
HNF-SD-WM-FHA-018, Rev. 1 Page 12

[2] Gauglitz, P. A., et al., 1994, Mechanisms of Gas Bubble Retention, Pacific Northwest Laboratory, PNL-10120/UC-510.

[3] Hodgson, et a1., 1995, Evaluation of Hanford Tanks for. Trapped Gas, Westinghouse Hanford Company, WHC-SD-WM-ER-526.

[4] Nichols, B. D., Eisenhawer, S. W., Spore, J. W., 1994, Bounding Gas Release Calculations of Flammable Gas Watch List Single Shell Tanks, Los Alamos National Laboratory, LA-UR-94-1323/TSA-6-94-R142.

[5] National Fire Protection Association 101, 1994, Life Safety code.

[6] Sullivan, H. L. et al., A Safety Assessment for Proposed Pump Mixing Operations to Mitigate Episodic Gas Releases in Tank 24I-SY-101: Hanford Site, Richland, WA., Los Alamos National Laboratory, LA-UR-92-3196, Rev. 14. 
HNF-SD-WM-FHA-018, Rev. I

Page 13

\section{ATTACHIMENT 1}




\section{CORRESPONDENCE DISTRIBUTION COVERSHEET}

Author

DE Trader/RL
Adoresset

President/KHC
Correspandence *o.

Incoming: 9308450

XREF: 9358502

SQject: CONCURRENCE FOR INTERPRETATION OF DOE STANDARD EV-OO43 "STANDARD ON FIRE PROTECTION FOR PORTABLE STRUCTURES, "AUGUST 1979

\section{INTERNAL DISTRIBUTION}

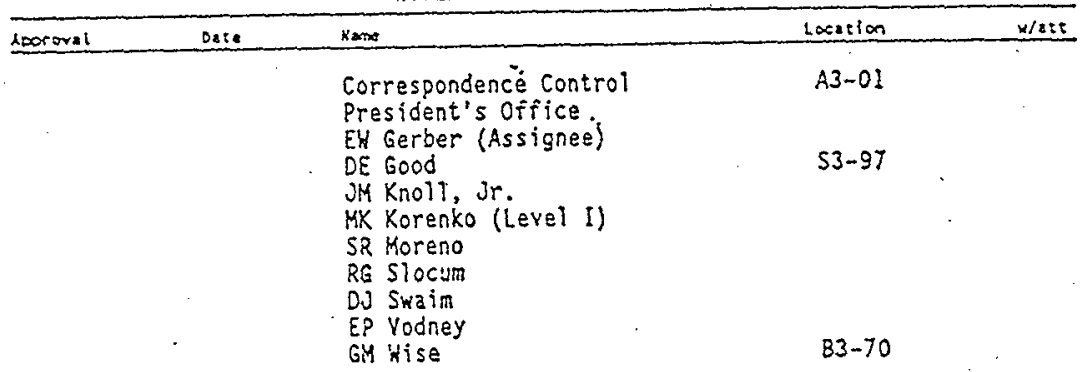

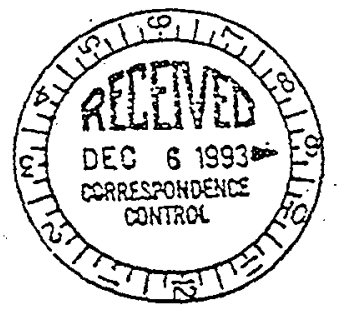

Distribution corrections: Marian Cram, 376-4123, Debbie Romine, 376-4804 or Doris Hartley, 376-8111

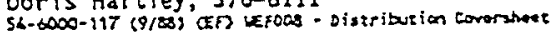




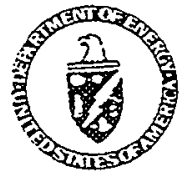

94-T00-016

\section{Department of Energy}

P.O. Box 550

Richlard, Wastirgton 92352

\section{inol $\leq 01993$}

Richland Field Office
President

Westinghouse hanford Company

Richland, Washington

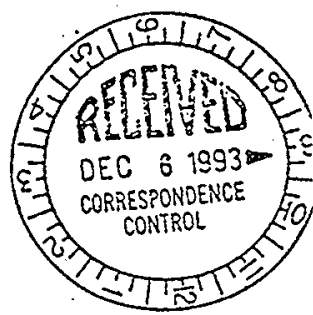

Dear Sir: PROTECTION FOR PORTABLE STRUCTURES," AUGUST 1979

Reference: WHC Letter \#9358602 to Mr. Keating, from Eric Gerber, "Concurrence for Interpretation of DOE Standard EY-0043," dated October 8, 1993

The Department of Energy, Richland Operations office has reviewed the referenced letter and concurs with the WHC interpretation of DOE Standard EV-0043 "Standard on Fire Protection for Portable Structures." "This standard provides an exception requiring good juogement be apolied by the Authority Having Jurisdiction (AKJ), a function of DOE-RL in accordance with DOE RLIP 5480.7 , in the enforcement of the standard.

If you have any questions, please contact Dennis Brown of my staff on (509) $372-4030$.

$$
\text { Sincerely, }
$$

D. E.Madur

D. E. Trader Technical Program officer

TDD:DET
Technology Development Division 
HNF-SD-WH-FHA-018, Rev. 1 Page 16

\section{CORRESPONDENCE DISTRIBUTION COVERSHEET}

\section{Author}

E. W. Gerber.
Adoressee

John J. Keating
Correspondence. Ho.

9358602

Subjecs: CONCURRENCE FOR. INTERPRETATION OF DOE STANDARD EV-0043

\begin{tabular}{|c|c|c|c|c|}
\hline \multicolumn{5}{|c|}{ INTERNAL DISTRIBUTION } \\
\hline sporoval & Dote & Yane & Locasion & $w / a t t$ \\
\hline \multirow{9}{*}{. } & & Correspondence Control & $A 3-01$ & $x$ \\
\hline & & RH Boger: & $L 4-90$ & $x$ \\
\hline & & SJ Eberle in & 15-55. & $x$ \\
\hline & & EW Gerber & $\lfloor 5-62$ & $x$ \\
\hline & & RD Lichfield & $\lfloor 6-5 \mid$ & $x$ \\
\hline & & RE Raymond & $R 2-54$ & $x$ \\
\hline & & JW Whattam & $14-90$ & $x$ \\
\hline & ${ }^{\circ}$ & MJ Wiemers & $N 1-21$ & $x$ \\
\hline & & Wo Winkelman & $\lfloor 5-55$ & $\dot{x}$ \\
\hline
\end{tabular}


P.O. Box 1970 Richland. WA 99352

October 8,1993

John J. Keating, Assistant Manager

Technology Supoort

U.S. Department of Energy

Richland Operations office

Richland, Washington 99352

Dear Mr. Keating:

CONCURRENCE FOR INTERPRETATION OF DOE STANDARD EV-0043" STANDARD ON FIRE PROTECTION FOR PORTABLE STRUCTURES," AUgUST 1979.

Reference: (1) DOE Standard EV-0043 "Standard on Fire Protection for

Attached is a report requesting concurrence of WHC's interpretation of DOE Standard EV-0043 "Standard on Fire Protection for Portable Structures" as it relates to the trailer outlined in this report. This standard provides an exception requiring good judgement be applied by the Authority Having Jurisdiction (AHJ), a function of DOE-RL in accordance with DOE RLIP 5480.7 , in the enforcement of the Standard. WHC hereby requests that this report be reviewed by the AHJ for concurrence of our interpretation and application of this exception.

This report is an updated version of the one previousiy sent for your review, and supercedes the previous letter. The update is necessary to reflect recent changes to this trailer. A new shell has been purchased and some items have been deleted or modified. A copy of this letter has been routed to D. E. Trader, DOE program manager for this project.

Because of the delays in the routing of our first report, we have been diligent in gaining concurrence from all whom are involved with this project at both WhC and DOE. Furthermore, ail involved have indicated WHC's interpretation will be granted concurrence aod are awaiting a formal response. 
John J. Keating

Page 2

October 8, 1993

I appreciate your efforts in this matter. Should you have any additional questions, please contact Susan Eberlein on 376-5029.

sincerely,

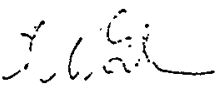

Eric Gerber, Manager

Engineering Development

Engineered Applications

sje

Attachment

RL - R. A. Holten

C. P. Christenson

D. E. Trader

R. O. Puthoff $w / 0$ attachment 


\title{
REQUEST FOR CONCURRENCE ON
}

\author{
INTERPRETATION OF
}

DOE STANDARD EV $\cdot 0043$

\section{STANDARD ON FIRE PROTECTION FOR}

\author{
PORTABLE STRUCTURES
}

Prepared by:

Jeff Whattam

Electrical Power Systems

Kestinghouse Hanford Company

September 23, 1993
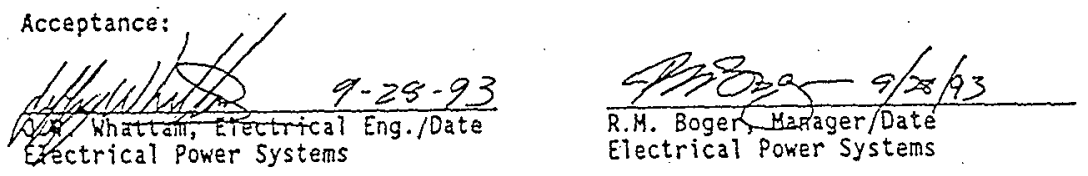

$\frac{2.040 .9-28-93}{\text { S.J. Eberiein, Principal Inv. Date }}$

Characterization Methods \& Devices

m. U. Ui $5 / 28 / 53$

A.J. Wiemers, Kanager/0ate

Gopjed Systems Development

\section{R.M. Bogen Narager/Date \\ Electrical Power Systems}
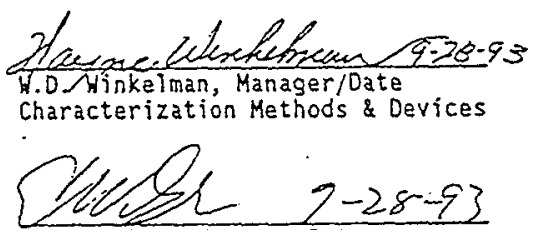

E. W. Gerber, Manager/Date Engineering Development

O. B. Evametor $9 / 29 / 93$

R.D. Lichfield, Manager/Date

Fire Protection Programs

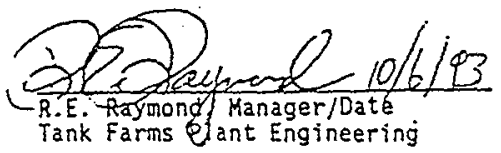




\section{INTRODUCTION}

This report has been written to obtain concurrence from the local Authority Having Jurisdiction (AHJ) with Hestinghouse Hanford Company's (HHC) interpretation of DOE EV-0043, Standard on Fire Protection for Portable structures. This standard requires the application of evacuation alarms, automatic sprinklers, and other fire safety guidelines for all portable structures in a single fire area where any one of the following conditions exists:

1. Creates a life hazard

2. Endangers the public or environment

3.: Repiacement value exceeds $\$ 250,000$ (structure and contents)

4. Is vital to a DOE program.

WHC is planning to develop and utilize a mobile instrumentation trailer as a technology demonstration station. This trailer will eventually be deployed at various tank farms and other locales within the Manford site. This trailer, termed the Light Duty Utility Arm (LDUA) Operations Control trailer, will have a value exceeding 5250,000 , but it will not pose any danger to the public or environment, nor is it vital to any DOE program.

While the LDUA trailer falls under the definition of a portable structure, DOE EV-0043 indicates the requirements were developed for portable structures that will be utilized at a particular location for an extended period. The. definition given for portable structure in this standard includes all trajiers and relocatable structures but states that they "...usualiy include installed utilities," which will not be the case for this trailer. This standard also contains an exception which states:

There are certain portable structures that, due to the nature of their operation, are moved frequently (usually several times a year). It is impractical to enforce this standard in its entirety on such portable structures. In such cases, the local fire protection authority having jurisdiction. should use good judgement in the application of this standard.

WHC believes that the LDUA trailer meets this exception, and therefore is not subject to the requirements of this standard. In addition, because of its intended uses, operations, and value, it would be impractical to implement such requirements for this trailer. The details of this trailer and its uses, operations, and value are outlined below.

\section{DISCUSSION}

The LOUA trailer will be a new, comaercially available, tandem axle, air ride, utility van modified to house computer and other monitoring systems. It will. 
HNF-SD-WM-FHA-018, Rev, I Page 21

Request For Concurrence on Interpretation of DOE Standard EY-0043

be 8.5 feet wide by 48 feet long with a maximum height of 13.5 feet. The trailer shell. will be constructed to meet Department of Transportation requirements as defined in Title 49 Code of Federal ReguTations Part 396 . It will travel to different tank farms and locales within the Hanford site serving as a mobile instrumentation trailer. The total value including the trailer and the computer equipment is estimated to be between \$700-5800K. The actual value during any operating period may be below this estimate as some missions may not require a full complement of equipment.

\section{USES}

The LDUA trailer will be used as a technology demonstration station. It will serve as a monitoring station for data acquisition and a control center for certain robotic manipulators and equipment. - It does not affect or satisfy any TPA milestones nor pose any environmental or safety hazards. While it will control equipment within a particular tank, this equipment must meet failsafe conditions and upon loss of power to the trailer (which could result other than by fire) must not pose any hazards.

\section{OPERATIONS}

This trailer will be of a mobile nature perhaps moving several times a year as conditions warrant. When operating at any location, it will normaliy only. function during the day shift (any required night operations will ba held to a minimum). While power may not always be disconnected at night, it will only serve minimal loads as required to maintain proper functioning of the on board systems. Specifically, this will include powering the heating, ventilation and air coriditioning system (KVAC) as needed to maintain the proper environment for the on board computers and monitoring systems. This HVAC system will be supplied from its own separate power panel adequately rated for this function.

\section{CONSTRAINTS}

Because of the nature of its operations, there are several constraints that make installing a fire protection system impractical. Upon loss of power, a fire alarm system would indicate a continuous trouble alarm and-alert authorities. As the trailer will have electrical power disconnected frequently, a separate, continuous power supply would be needed for an automatic fire detection system. Such a system is not readity achievable with the current design of this trailer. Furthermore, there are no practical automatic fire suppression systems that could be utilized. Water for fire suppression will not be available at many of the Iocations, Carbon Dioxide could harm the occupants, and the use of Haion has been discontinued by DOE. 
HNF-SD-WM-FHA-018, Rev. 1 Page 22

Request For Concurrence on Interpretation of DOE standard EY-0043

\section{SAFETY PRECAUTIONS}

Appropriate operating procedures will be established for this trailer to ensure safe operating conditions. Properly trained personnel will be required to hook up the required power feed to the trajler. A readily available manual disconnect switch will be provided to safely de-energize the trailer. A window will be installed for additional light and to aid visibility during egress. No sleeping quarters will be provided and smoking will be prohibited. High power instrumentation racks will be hardwired to avoid any overloads on the receptacle circuits. A cellular telephone will be installed and available for emergency use, and the trailer will be equipped with required portable fire extinguishers. All personnel will be trained for their functions and in trailer safety. Trailer design and modifications or additions will be buit to NFPA 101 "Life Safety Code" and NFPA 70 "National Electric Code" standards.

\section{SUMMARY}

Based on the above conditions, no practical or cost-effective means exists to install and implement an automatic fire protection system for the LOUA trailer. In the WHC interpretation of DOE EV-0043, this portable structure falls under the listed exception and requires no automatic fire protection. system be installed. Therefore, WHC requests DOE-RL concurrence, as the . Authority Having Jurisdiction, that this interpretation is correct. 